\title{
Conductivity, electric field and electron drift velocity within the equatorial electrojet
}

\author{
R. G. Rastogi and H. Chandra
}

Physical Research Laboratory, Navrangpura, Ahmedabad 380 009, India

(Received June 6, 2005; Revised March 16, 2006; Accepted April 5, 2006; Online published September 16, 2006)

\begin{abstract}
Rocket-borne in-situ measurements of electron density and current density made from Thumba, India, on four occasions between 1966 and 1973 and on one flight from Peru in 1965 are studied along with the corresponding ground magnetometer data. The Cowling conductivity is computed using the yearly mean magnetic field values of 1965 and the atmospheric density values from the MSIS 1986 model. The rocket-borne measurements from Thumba cover different geophysical conditions of strong, moderate and partial counter-electrojet events. The vertical profiles of the measured current density and electron density are presented along with the computed Cowling conductivity, electron drift velocity and electric field. The peak current density occurred at 106-107 km over Thumba and at $109 \mathrm{~km}$ over Peru compared to $104 \mathrm{~km}$ over Brazil. Cowling conductivity peaks occurred at $102 \mathrm{~km}$ over Huancayo and $101 \mathrm{~km}$ over Thumba, while electron drift velocity and electric field peaks occurred at approximately 105-107 km over Thumba, 108 and $110 \mathrm{~km}$ over Huancayo and $104 \mathrm{~km}$ over Brazil, respectively. While the electron density near the level of peak current density shows some variability, electron drift velocity and electric field show large variability. We conclude that the local electric field plays an important role in the spatial and temporal variability of the strength of the electrojet.
\end{abstract}

Key words: Equatorial electrojet, equatorial ionosphere.

\section{Introduction}

Enhancement of the solar daily range of the horizontal component of the geomagnetic field $H$, as detected above Peru, was explained by Chapman (1951) as being due to a band of intense electric current in the $E$-region of the ionosphere within $\pm 3^{\circ}$ dip latitude; subsequently denoted as the Equatorial Electrojet (EEJ). The unique geometry of the orthogonal electric and magnetic fields and the different vertical mobility of electrons and ions in the $E$-region cause a vertical Hall polarization field, which in turn increases the electrical conductivity over the magnetic equator (Cowling and Borger, 1948). This causes a large current over the dip equator with the same dynamo electric field that found at other latitudes (Baker and Martyn, 1953). For orthogonal magnetic and electric fields $B$ and $E$, respectively, and in the absence of collisions, both electrons and ions move with the same velocity in a direction perpendicular to both that is expressed by

$$
V_{d}=E \times B / B^{2}
$$

with no current flow. However, in the presence of collisions electrons move faster than the ions, causing a vertical Hall Polarization field. This vertical Hall Polarization field is restricted to a few degrees around the dip equator and increases the Cowling conductivity. The enhanced East-West Cowling conductivity $\sigma_{3}$ is given by

$$
\sigma_{3}=\sigma_{1}\left[1+\left(\sigma_{2} / \sigma_{1}\right)^{2}\right]
$$

Copyright (c) The Society of Geomagnetism and Earth, Planetary and Space Sciences (SGEPSS); The Seismological Society of Japan; The Volcanological Society of Japan; The Geodetic Society of Japan; The Japanese Society for Planetary Sciences; TERRAPUB where $\sigma_{1}$ is the Pederson conductivity and $\sigma_{2}$ is the Hall conductivity. At $100 \mathrm{~km}$ the ratio $\sigma_{2} / \sigma_{1}$ is about 30 , indicating that the Cowling conductivity is about two orders of magnitude larger than the Pederson conductivity.

The electrojet current density $J_{e}$ is related to the electron density $n_{e}$ by the equation

$$
J_{e}=n_{e} \cdot e \cdot V_{d}
$$

where $e$ is the electronic charge and $V_{d}$ the electron drift velocity. The current density is also related to the Cowling conductivity,

$$
J_{e}=\sigma_{3} \cdot E .
$$

Therefore if simultaneous measurements of current density and electron density are available, drift velocity and electric field can be computed from Eqs. (3) and (4) respectively.

Pfaff et al. (1997) made simultaneous rocket-borne insitu measurements of vector DC electric field, current density and plasma density in the daytime equatorial electrojet from Alcantara, Brazil. Good agreement was found between the magnitude and the profile of plasma drifts calculated independently from $E_{\text {vert }} / \mathrm{B}$ and $J_{\text {zonal }} / q N e$.

Investigations on the EEJ have traditionally been based on the measurements of the horizontal $(H)$ and vertical $(Z)$ components of geomagnetic field, which are known to be affected by various currents in the ionosphere and magnetosphere, especially during disturbed conditions in the magnetic field. Consequently, the determination of variations in the EEJ during different conditions was not possible. The ionospheric drift measurements carried out by the spaced receiver method has provided data on the EEJ that were not 
vitiated by disturbances. An extensive set of ionospheric drift measurements made over the dip equator in India over a 5-year period remains the only long series of data available anywhere in world. The drifts at Thumba (India) have been shown to be a better index of EEJ than the geomagnetic $H$ field (Chandra et al., 1971; Rastogi et al., 1972).

The Thumba data set also provided the first conclusive evidence that the equatorial electric field decreases with the increase in geomagnetic activity, described by the index $K_{p}$ (Rastogi et al., 1971b), and established for the first time that a direct relation exists between the EEJ and the interplanetary magnetic field component normal to the ecliptic (Rastogi and Chandra, 1974). The disappearance of the $E$ region ionospheric irregularities $\left(E_{\mathrm{sq}}\right)$ during the daytime at times of depressions in the geomagnetic $H$ field below the night time base level, which is known as the counterelectrojet (CEJ), has been shown to be associated with the reversal of the equatorial electric field, as indicated by the change in the ionospheric drift from the westward to the eastward direction (Rastogi et al., 1971a).

Fambitakoye et al. (1973) compared the latitudinal profiles of the regular daily magnetic variations, $S_{R}$, of the $H$ and $Z$ components from a meridional chain of nine magnetometers across central Africa with corresponding quarterhourly ionogram/sequences from Fort-Archambault, an electrojet station. This group found that the disappearance of $E_{\mathrm{sq}}$ traces coincided exactly with the reversals in the $S_{R}$ variations of the $H$ and $Z$ fields.

Subsequent investigations revealed that $E_{\mathrm{sq}}$ irregularities over Thumba occasionally disappeared when $\Delta H$ showed a depression not decreasing below the nighttime level, although the irregularities were still associated with the reversal of the direction of the ionospheric $E$-region drift. These events are called partial counter-electrojet. Rastogi (1975) suggested that the $\Delta H$ observed at ground level at a station close to the magnetic equator was the combined effect of two simultaneous $E$-region currents flowing at different altitudes: (1) part of the global $S_{q}$ current system due to tidal oscillations of the ionosphere flowing eastward during the daytime at a altitude of 106-107 km and (2) a pure equatorial component flowing at $100 \mathrm{~km}$ eastward during the normal electrojet but westward during full or partial counter electrojet events. Simultaneous opposite flowing electric currents at different altitudes have been experimentally observed by Carter et al. (1976) from Doppler VHF radar measurements in western Africa. The additional westward electric field during CEJ events is of tidal origin for slow events and of magnetospheric origin during fast events.

Using high time resolution VHF Doppler radar data at Thumba with the $H$ field data at Trivandrum (TRD) and Alibag (ABG), Rastogi and Patil (1986) showed that there was an excellent correlation between the Doppler shift and $\Delta H$ (TRD) $-\Delta H$ (ABG) during quiet as well as during severe geomagnetic storms. These researchers concluded that $\Delta H$ (TRD-ABG) is the best index for the EEJ component of equatorial ionospheric currents.

We report a study of the equatorial electrojet (EEJ) using the in situ rocket-borne measurements of plasma density and current density from Thumba (India) and Peru along with the ground magnetometer data. The vertical profiles of the measured current density and electron density from published data are presented along with the computed Cowling conductivity, electron drift velocity and electric field. The Cowling conductivity is computed using the yearly mean magnetic field values of 1965 , and the atmospheric density values were obtained from the MSIS 1986 model as described by Sinha et al. (1999).

\section{Data and Results}

The measurements of the electrojet currents and electron density from Thumba had been reported earlier. Vertical profiles of current density were obtained using the proton precession or rubidium vapour magnetometers (Sastry, 1968, 1970, 1973). The electron density measurements were made using a new Langmuir probe system, which works on a single floating battery (Prakash and Subbaraya 1967), developed at the Physical Research Laboratory. The probe system with reduced leakage currents and thorough pre-launch check-out has several advantages. The first successful flight was on 7 July 1966 with a nose-tipped sensor in a sweep mode $(-2.4$ to $+2.4 \mathrm{~V}$ in $0.5 \mathrm{~s}$ followed by 1.5 $\mathrm{s}$ of fixed bias at $+2.4 \mathrm{~V}$ ); later flights used a more or less standardized form with a fixed bias at $+4.0 \mathrm{~V}$. The conversion of the probe current to electron density was calibrated using the critical frequency of the $E$ region, $f_{o} E$, from the ionosonde at Thumba (for twilight period) or Kodaikanal (around midday). The calibration using ionosonde data at Kodaikanal agrees within the experimental errors (10\%). Absolute values of electron densities were also obtained over Thumba on two occasions using a resonance probe (Rao and Prakash, 1978). Subbaraya et al. (1983) have described the probe and calibration details and electron density values at every kilometre interval for 25 rocket flights (12 during daytime) in the period 1966-1978 using heightdependent calibration. Sinha and Prakash (1996) have reported electron density profiles for 17 daytime rocket flights from Thumba. In the present report we have taken current density values for Thumba from the published profiles, while electron density values are taken from the tabulated values reported by Subbaraya et al. (1983). The current density and electron density values for Peru are taken from published profiles (Maynard, 1967).

The results of the rocket-borne magnetometer and electron density measurements from Thumba on 29 August 1968 are shown in Fig. 1. The daily variations in the horizontal component of the geomagnetic field at TRD and $\mathrm{ABG}$ and the difference between the two, which is a measure of the electrojet strength, are shown in Fig. 1(a). The maximum range in $H$ was $112 \mathrm{nT}$ at 1030 hours $\left(75^{\circ} \mathrm{EMT}\right)$ at TRD and $39 \mathrm{nT}$ at $1200 \mathrm{~h}$ at ABG. The electrojet strength was $90 \mathrm{nT}$ at 1000 hours. The equatorial current therefore comprised $90 \mathrm{nT}$ of the electrojet component and $39 \mathrm{nT}$ of the global $S_{q}$ current. Thus, that day can be considered to be a strong electrojet day. At the time of the rocket launch at 1345 hours $\Delta H$ was $70 \mathrm{nT}$ at TRD and $28 \mathrm{nT}$ at ABG, a difference of $42 \mathrm{nT}$. Consequently, the electrojet portion was larger than the $S_{q}$ portion of the current.

The vertical profiles of the measured current density $(J)$, electron density $(N)$ and computed values of the Cowling conductivity $\left(\sigma_{3}\right)$, electron drift velocity $\left(V_{d}\right)$ and electric 
(b)

Thumba, 29 August 1968
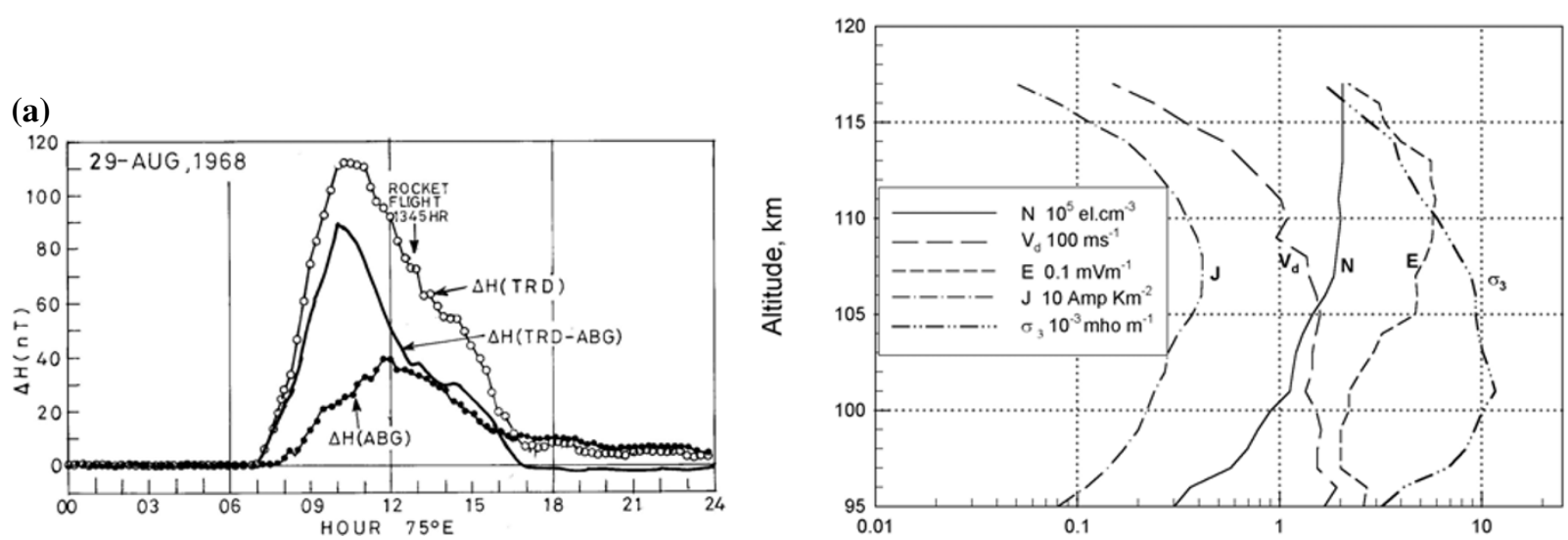

Fig. 1. (a) Daily variations of the geomagnetic $H$ field $(\Delta H)$ at Trivandrum and Alibag and of the differences at two stations on 29 August 1968 . The time of the rocket launch is also marked in the figure. (b) Vertical profiles of the rocket-borne in-situ measured current density $(J)$, electron density $(\mathrm{N})$ and the computed Cowling conductivity $\left(\sigma_{3}\right)$, electron drift velocity $\left(V_{d}\right)$ and electric field $(E)$ on 29 August 1968 from Thumba.

field $(E)$ are shown in Fig. 1(b). The current density increases steadily from $95 \mathrm{~km}$ to a maximum value of 4.2 Amp $\mathrm{km}^{-2}$ at $107 \mathrm{~km}$ and decreases thereafter. The electron density, which was $0.24 \times 10^{5} \mathrm{el} . \mathrm{cm}^{-3}$ at $95 \mathrm{~km}$, increases steadily to a value of $2.0 \times 10^{5}$ el. $\mathrm{cm}^{-3}$ at 115 $\mathrm{km}$. The Cowling conductivity, which peaks at $101 \mathrm{~km}$, is $11.7 \times 10^{-3} \mathrm{mho} \mathrm{m}^{-1}$. The electron drift velocity remains fairly constant up to $105 \mathrm{~km}$ and then decreases steadily with maximum of $160 \mathrm{~m} / \mathrm{s}$ at $105 \mathrm{~km}$. The electric field shows a minor peak of $0.48 \mathrm{mV} \mathrm{m}^{-1}$ at $106 \mathrm{~km}$ and a major peak of $0.59 \mathrm{mV} \mathrm{m}^{-1}$ at $111 \mathrm{~km}$. Thus, while the Cowling conductivity is at its maximum at $101 \mathrm{~km}$, the current density is at its maximum at $107 \mathrm{~km}$. The explanation for this is that both electron density and electric field are larger at $107 \mathrm{~km}$ than at $101 \mathrm{~km}$.

There were two additional rocket flights at 1048 and 2230 hours, respectively, for current density measurements only on 29 August 1968. The altitude profiles of the current density for all three flights on 29 August 1968 are shown in Fig. 2. At the morning flight time of 1048 hours the $\Delta H$ values were $110 \mathrm{nT}$ at TRD and $37 \mathrm{nT}$ at $\mathrm{ABG}$, with the electrojet strength then $73 \mathrm{nT}$. The electrojet current component was therefore larger at 1038 than at 1345 hours even though the $S_{q}$ parts of the current were of same magnitude at both times. The value of peak current density at 1038 hours was 9.0 Amp km${ }^{-2}$, while at 1345 hours it was 4.2 Amp km ${ }^{-2}$. However, the altitudes of the peak current density were the same for the two flight times. The rocket flight at 2230 hours was at the late night hours when the electrojet current is assumed to be absent. The observed altitude profile of current density at this time shows slow random fluctuations around the zero value, suggesting the absence of any significant current.

Results for the rocket-borne measurements made at 1229 hours on 13 October 1972 along with geomagnetic $H$ field variations are shown in Fig. 3(a, b). The peak $\Delta H$ value was $116 \mathrm{nT}$ at 1100 hour for TRD and $33 \mathrm{nT}$ at 1330 hours for ABG. At the time of the rocket launch at 1229 hours, $\Delta H$ at Trivandrum was $105 \mathrm{nT}$, of which $84 \mathrm{nT}$ was due to the electrojet component and $21 \mathrm{nT}$ due to the $S_{q}$ current

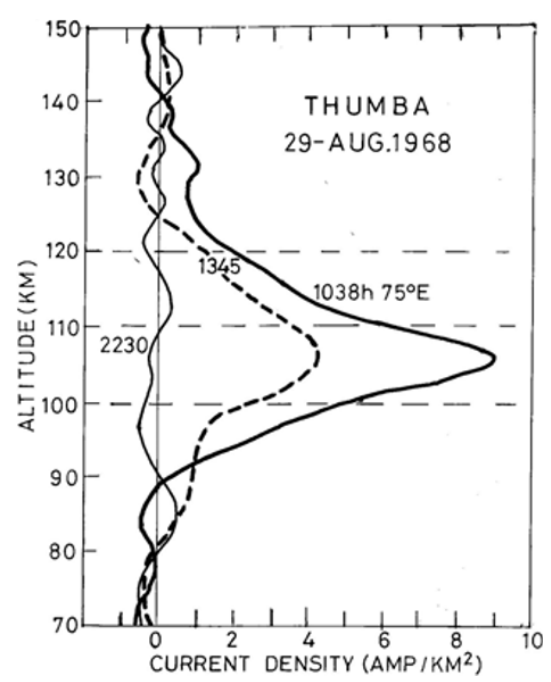

Fig. 2. Vertical profiles of the current density from the three rocket flights conducted from Thumba at $1038 \mathrm{~h}, 1345 \mathrm{~h}$ and $2230 \mathrm{~h}$ on 29 August 1968.

component. Thus, the electrojet current component is much larger than the global $s_{q}$ current in this case. The altitude profile of the current density shows a maximum value of 9.6 Amp km ${ }^{-2}$ between 105 and $106 \mathrm{~km}$. As its value is only $4.5 \mathrm{Amp} \mathrm{km} \mathrm{km}^{-2}$ at $100 \mathrm{~km}$, the ratio for the $S_{q}$ /electrojet current is 0.47 . The corresponding ratio of $\Delta H\left(S_{q}\right) / \Delta H$ (electrojet) is 0.25 . The electron density increases from $0.37 \times 10^{5} \mathrm{el} . \mathrm{cm}^{-3}$ at $95 \mathrm{~km}$ to $1.26 \times 10^{5} \mathrm{el} . \mathrm{cm}^{-3}$ at 106 $\mathrm{km}$, increasing slowly at higher altitudes. The Cowling conductivity peaks at $100 \mathrm{~km}$ with a value of $10.8 \times 10^{-3}$ mho $\mathrm{m}^{-1}$. The electron drift increases from a value of 270 $\mathrm{m} / \mathrm{s}$ at $95 \mathrm{~km}$ to $491 \mathrm{~m} / \mathrm{s}$ at $105 \mathrm{~km}$ and then decreases steadily to $60 \mathrm{~m} / \mathrm{s}$ at $120 \mathrm{~km}$. The electric field value is 0.4 $\mathrm{mV} \mathrm{m}^{-1}$ at $95 \mathrm{~km}$, increasing steadily to $1.36 \mathrm{mV} \mathrm{m}^{-1}$ at $106 \mathrm{~km}$, thereafter remaining fairly constant with altitude. Thus, once again the current density peaks at 105-106 km compared to the peak in conductivity at $100 \mathrm{~km}$. In this case the electric field at $105-106 \mathrm{~km}$ is much higher than that at 
(b)

Thumba, 13 October 1972

(a)
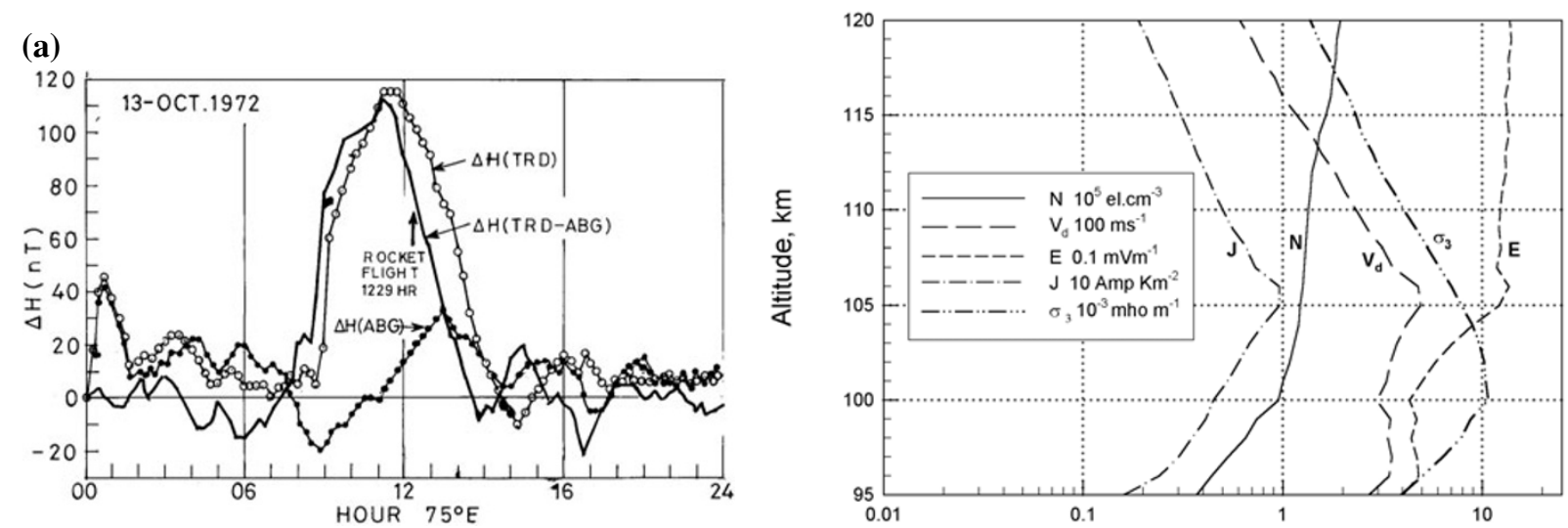

Fig. 3. (a) Daily variations of the geomagnetic $H$ field $(\Delta H)$ at Trivandrum and Alibag and of the differences at two stations on 13 October 1972 . The time of the rocket launch is also marked in the figure. (b) Vertical profiles of the rocket-borne in-situ measured current density $(J)$, electron density $(N)$ and the computed Cowling conductivity $\left(\sigma_{3}\right)$, electron drift velocity $\left(V_{d}\right)$ and electric field $(E)$ on 13 October 1972 from Thumba.

(b)

Thumba, 3 March 1973

(a)

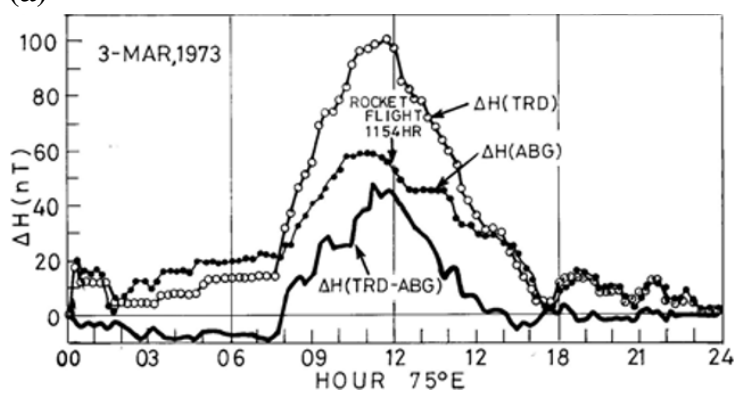

\section{0}

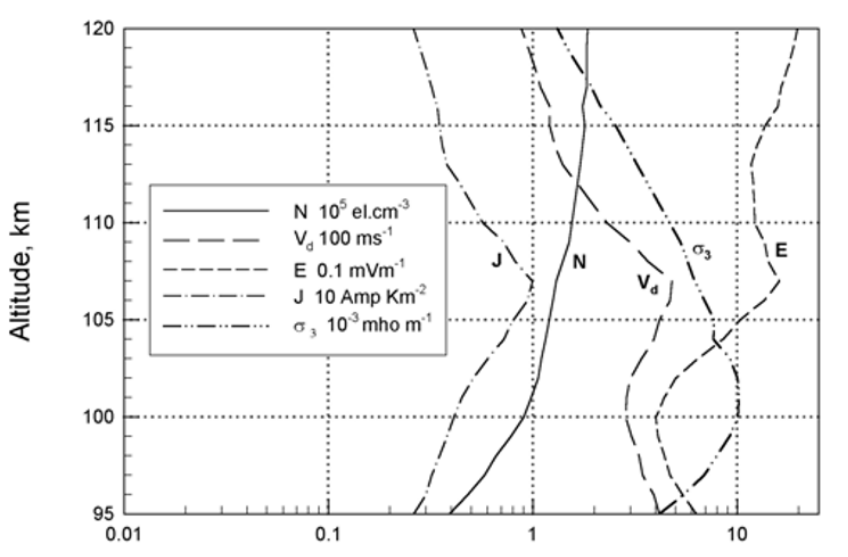

Fig. 4. (a) Daily variations of the geomagnetic $H$ field $(\Delta H)$ at Trivandrum and Alibag and of the differences at two stations on 3 March 1973 . The time of the rocket launch is also marked in the figure. (b) Vertical profiles of the rocket-borne in-situ measured current density $(J)$, electron density $(N)$ and the computed Cowling conductivity $\left(\sigma_{3}\right)$, electron drift velocity $\left(V_{d}\right)$ and electric field $(E)$ on 3 March 1973 from Thumba.

$101 \mathrm{~km}$. Electron drift velocity is also higher at 105-106 $\mathrm{km}$.

The results for the rocket flight conducted at 1154 hours on 3 March 1973 along with the geomagnetic $H$ field variations are shown in Fig. 4(a, b). The maximum value of $\Delta H$ was $101 \mathrm{nT}$ at 1130 hours for TRD and $59 \mathrm{nT}$ at 1100 hours for $\mathrm{ABG}$, giving an electrojet strength of $42 \mathrm{nT}$. The electrojet strength at the time of rocket launch was $45 \mathrm{nT}$. The current density profile shows a maximum value of $10 \mathrm{Amp}$ $\mathrm{km}^{-2}$ at $107 \mathrm{~km}$. The electron density increases steadily from a value of $3.9 \times 10^{4} \mathrm{el} . \mathrm{cm}^{-3}$ at $95 \mathrm{~km}$ to a value of $1.3 \times 10^{5} \mathrm{el} . \mathrm{cm}^{-3}$ at $107 \mathrm{~km}$. The Cowling conductivity peaks at $101 \mathrm{~km}\left(10.3 \times 10^{-3} \mathrm{mho} \mathrm{m}^{-1}\right)$. The electron drift velocity increases from a value of $285 \mathrm{~m} / \mathrm{s}$ at $100 \mathrm{~km}$ to a peak at $107 \mathrm{~km}$ with a value of $480 \mathrm{~m} / \mathrm{s}$ and then decreases steadily to $88 \mathrm{~m} / \mathrm{s}$ at $120 \mathrm{~km}$. However, there was an observed increase below $100 \mathrm{~km}$ with high values. The electric field value is $0.63 \mathrm{mV} \mathrm{m}^{-1}$ at $95 \mathrm{~km}$, which increases steadily to a peak value of $1.61 \mathrm{mV} \mathrm{m}^{-1}$ at $107 \mathrm{~km}$ and then increases once again from $113 \mathrm{~km}$ onwards.

The rocket launch on 7 July 1966 happened to take place during a partial CEJ event. The results for the rocket flight conducted at 1315 hours along with the geomagnetic $H$ field variations are shown in Fig. 5(a, b). Hourly values of the ground magnetic field measured at TRD and ABG along with the difference between the two are shown in Fig. 5(a). The variation of $\Delta H$ shows a peak value of $86 \mathrm{nT}$ at 1130 hours for the TRD data set. However the variation at ABG was unusual on that day, with a maximum value of $\Delta H$ at 1330 hours $(60 \mathrm{nT})$. The electrojet strength, described as the difference in $H$, showed a peak value of $42 \mathrm{nT}$ at 1100 hour, with later values falling below the baseline in the time frame from 1300 to 1600 hours. The rocket flight took place at 1315 hours when the difference in $H$ was about -10 $\mathrm{nT}$. The transparent type of sporadic- $E$ at Kodaikanal near the dip equator was present, implying there was no reversal of electric field or current at the time of the depression in $H$. The current density profile shows a broad peak with a value of $4.35 \mathrm{Amp} \mathrm{km}^{-2}$ at $106 \mathrm{~km}$. The electron density profile shows a value of $5.1 \times 10^{4} \mathrm{el} . \mathrm{cm}^{-3}$ at $95 \mathrm{~km}$, steadily increasing to a peak value of $1.92 \times 10^{5} \mathrm{el} . \mathrm{cm}^{-3}$ at $106 \mathrm{~km}$, followed by a very slow increase to $120 \mathrm{~km}\left(2.34 \times 10^{5} \mathrm{el}\right.$. 
(b)

Thumba, 07 July 1966

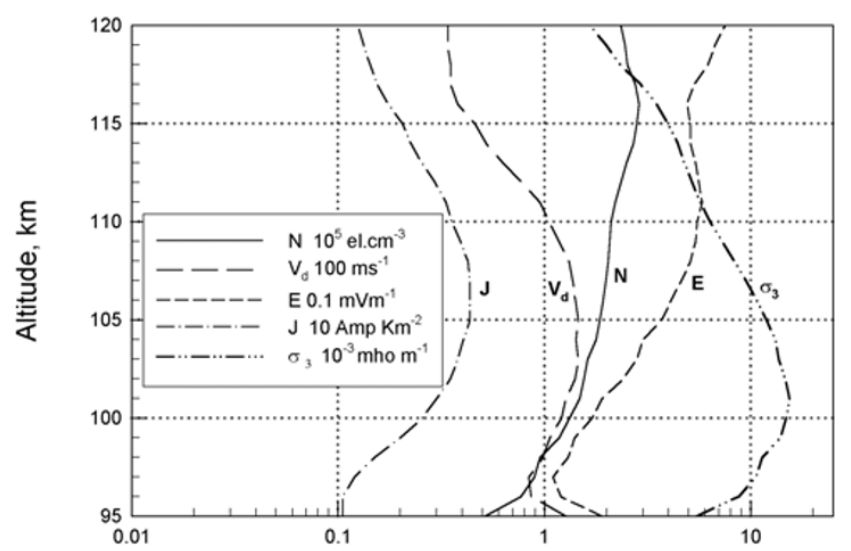

(a)

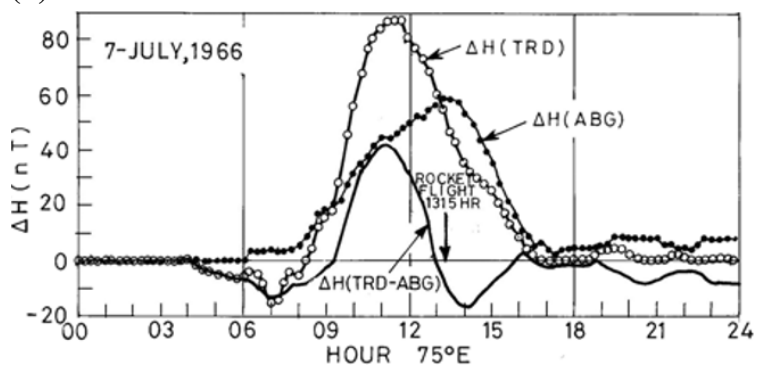

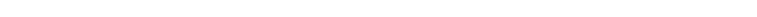

A Alibag and of the differences at two stations on 7 July 1966.

Fig. 5. (a) Daily variations of the geomagnetic $H$ field $(\Delta H)$ at Trivandrum and Alibag and of the differences at two stations on 7 July 1966 . The time of the rocket launch is also marked in the figure. (b) Vertical profiles of the rocket-borne in-situ measured current density $(J)$, electron density $(N)$ and the computed Cowling conductivity $\left(\sigma_{3}\right)$, electron drift velocity $\left(V_{d}\right)$ and electric field $(E)$ on 7 July 1966 from Thumba.
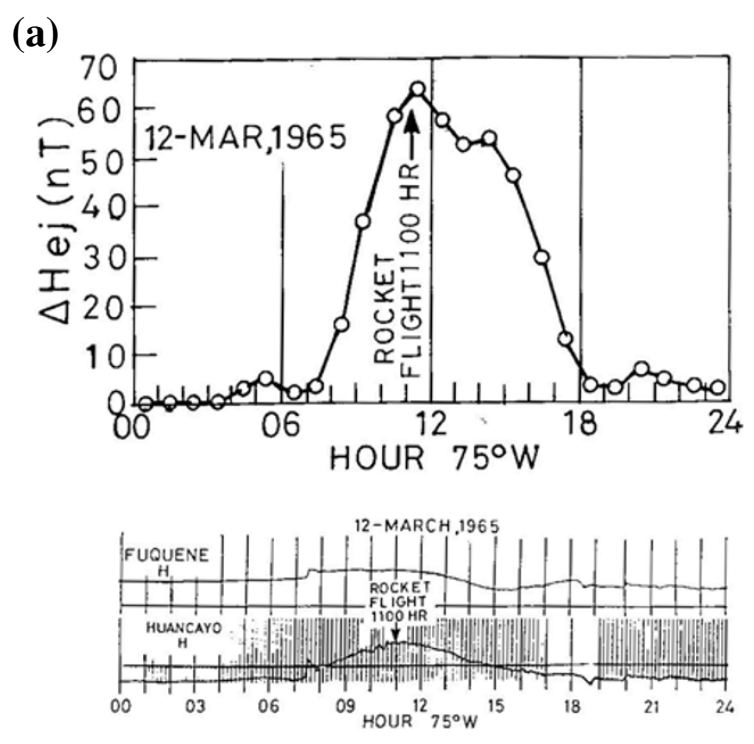

(b)

Huancayo, 12 March 1965

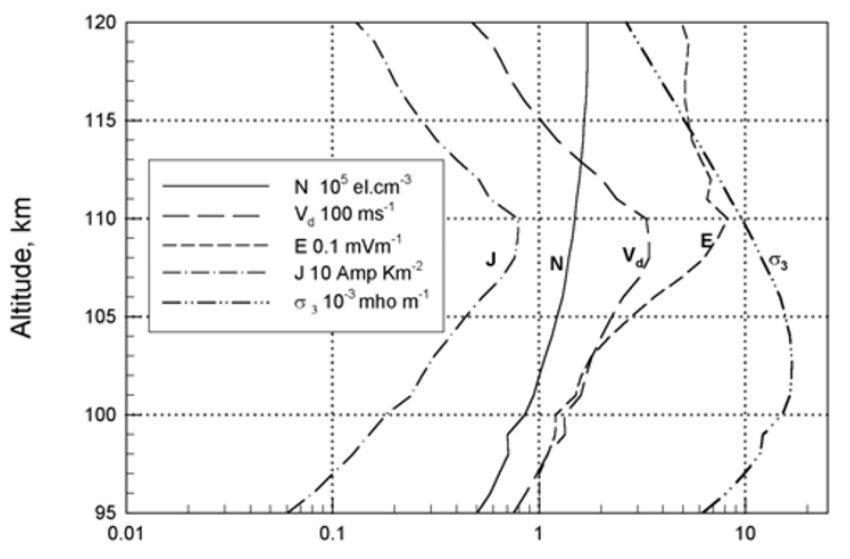

Fig. 6. (a) Daily variation of the difference in range in $H$ at Huancayo and Fuquene on 12 March 1965 along with the time of rocket launch marked (upper); Magnetograms of $H$ component for Huancayo and Fuquene on 12 March 1965 (lower). (b) Vertical profiles of the rocket-borne in-situ measured current density $(J)$, electron density $(N)$ and the computed Cowling conductivity $\left(\sigma_{3}\right)$, electron drift velocity $\left(V_{d}\right)$ and electric field $(E)$ on 12 March 1965 from Huancayo.

$\mathrm{cm}^{-3}$ ). The Cowling conductivity peak is at $101 \mathrm{~km}$, with a value of $15.6 \times 10^{-3} \mathrm{mho} \mathrm{m}^{-1}$. Electron drift velocity is $86 \mathrm{~m} / \mathrm{s}$ at $96 \mathrm{~km}$, increasing to a broad peak of $146 \mathrm{~m} / \mathrm{s}$ at $105 \mathrm{~km}$ and then decreasing steadily to $34 \mathrm{~m} / \mathrm{s}$ at 120 $\mathrm{km}$. The electric field increases from $0.19 \mathrm{mV} \mathrm{m}^{-1}$ at 95 $\mathrm{km}$ to a broad peak of $0.58 \mathrm{mV} \mathrm{m}^{-1}$ at $110 \mathrm{~km}$ and then steadily increases at higher altitudes. The electric field and drift values were smaller on this day.

The results of a rocket flight conducted from Peru on 12 March 1965 are shown in Fig. 6. The magnetograms of Huancayo and Fuquene are shown in the lower part of Fig. 6(a), while the difference in $H$ at the two locations is plotted in the upper part. The rocket was launched at 1100 hours $\left(75^{\circ} \mathrm{WMT}\right)$ near the peak of the electrojet strength $(64 \mathrm{nT})$. The vertical profiles of different parameters are shown in Fig. 6(b). The current density shows a maximum value of $7.9 \mathrm{Amp} \mathrm{km}^{-2}$ at $109-110 \mathrm{~km}$. The electron den- sity increases from $5 \times 10^{4}$ el. $\mathrm{cm}^{-3}$ at $95 \mathrm{~km}$ to $1.49 \times 10^{5}$ el. $\mathrm{cm}^{-3}$ at $110 \mathrm{~km}$, slowly increasing thereafter to $1.7 \times 10^{5}$ el. $\mathrm{cm}^{-3}$ at $120 \mathrm{~km}$. The Cowling conductivity peak is at $102-103 \mathrm{~km}$ with a value of $16.8 \times 10^{-3} \mathrm{mho} \mathrm{m}^{-1}$. The electron drift velocity increases from $75 \mathrm{~m} / \mathrm{s}$ at $95 \mathrm{~km}$ to a peak value of $350 \mathrm{~m} / \mathrm{s}$ at $108 \mathrm{~km}$, decreasing to $50 \mathrm{~m} / \mathrm{s}$ at $120 \mathrm{~km}$. The electric field peaks at $110 \mathrm{~km}\left(0.82 \mathrm{mV} \mathrm{m}^{-1}\right)$. Thus, the peak of current is at an altitude slightly higher than that observed in the Indian sector.

\section{Discussion}

Geomagnetic studies in India have been experimentally supported by the Kodiakanal ionosonde data since 1952. Values of the critical frequency of the $E$-layer $\left(f_{o} E\right)$ over Kodaikanal were published for few years based on the high-quality ionograms. Normalizing the range of $H$ with $N_{m} E$, the maximum electron density of the $E$-layer, Ras- 
togi (1993) suggested an index for the equatorial electric field $\left(\Delta H / N_{m} E\right)$. The solar cycle variation of $\Delta H$ at Kodaikanal was shown to be largely due to the corresponding variation in $N_{m} E$, while the seasonal variation was shown to be largely due the corresponding variation in the electric field. Consequently, variations in $N_{m} E$ and the electric field contributed equally to daily variations in the electrojet.

Subbaraya et al. (1972) described the results of the rocket-borne measurements from Thumba. It was concluded that in the EEJ the horizontal electric field is not constant with height and, in fact, probably increases with height, in the height region of the EEJ. The electric field ranged between 0.5 to $1.5 \mathrm{mV} / \mathrm{m}$. A similar conclusion was arrived at from measurements of the drift at Thumba using VHF backscatter radar. Tiwari et al. (2003) recently reported measurements of drift velocity of electrojet irregularities by VHF and HF radar from Thumba. Average velocities around noon showed a peak at $106 \mathrm{~km}$ for VHF and $109 \mathrm{~km}$ for HF measurements, while the mean peak drift velocities were around $260 \mathrm{~m} / \mathrm{s}$ for VHF and $240 \mathrm{~m} / \mathrm{s}$ for HF.

Pfaff et al. (1997) found a peak plasma drift velocity of $370 \mathrm{~m} / \mathrm{s}$ at $105 \mathrm{~km}$ from the plasma density and current profiles at Alcantara, Brazil, on 1 September 1994. The peak drift velocity from the electric field measurements was $390 \mathrm{~m} / \mathrm{s}$ at $104.5 \mathrm{~km}$.

This report compares the day-to-day variability results from the four days of rocket measurements conducted from Thumba. The current density peak varies from 4.15 to 9.5 Amp km ${ }^{-2}$, and the altitude of the peak varies from 105.5 to $107.5 \mathrm{~km}$. The low value on 29 August 1968 is due to the fact that the measurements were made at 1345 hours rather than at noon. The current density at 1048 hours on same day was higher. The lower value on 7 July 1966 was, however, due to the fact that it was a partial CEJ event. The drift velocity and electric field near the peak current density were higher for the March and October measurements but smaller for the July and August measurements. This is consistent with the fact that electrojet is strongest during equinoxes. While Cowling conductivity values differed very little among the flights conducted during March, October and August, the highest value occurred during July. The electron densities at the peak current density altitudes are less during equinoctial months than summer months $\left(1.3 \times 10^{5}\right.$ el. $\mathrm{cm}^{-3}$ compared to $\left.1.9 \times 10^{5} \mathrm{el} . \mathrm{cm}^{-3}\right)$. Therefore, the lower current densities in the summer months are associated with lower electric field and drift values. The electric field shows a large variability, ranging from about 0.4 to $1.6 \mathrm{mV} \mathrm{m}^{-1}$. Consequently, it can be concluded that the electric field plays an important role in the variability of the electrojet strength.

A number of models have been developed in attempts to explain the observed features of the EEJ (Untiedt, 1967; Sugiura and Poros, 1969). Richmond (1973) developed a numerical model that included winds and instabilities in which the physical features of the EEJ were examined. It was shown that the two-stream instability limits the strength of the polarization electric field and the eastward current. Changes in temperature, electron density, geomagnetic field and electron and ion collision frequencies were tested in the model to illustrate how currents are sensitive to conductivity distribution. An increase in the magnetic field strength was found to reduce the Pederson and Hall conductivities at all levels and also to lower the altitude of the maximum polarization field to a level where Hall conductivity is lower, thereby reducing the strength of the electrojet.

Gangepain et al. (1977) compared different models and showed that differences arise largely as a result of the different values of electron collision frequencies used. A model was devised by empirically adjusting the electron collision frequency so that it is in good agreement with observed parameters of the EEJ. A value that is fourfold that calculated from laboratory data correctly modeled the electrojet parameters. Ronchi et al. (1990) examined how the fully developed strongly turbulent state of the small-scale waves (tens of meters in size) affects large-scale dynamics. By including the additional mobility and diffusion factors and the small wave-length density fluctuations from in-situ rocket measurements made from Peru, these researchers showed that the equilibrium vertical electric field peaks around 100 $\mathrm{km}$ in the absence of turbulent terms and around $105 \mathrm{~km}$ in their presence. The peak value of the vertical polarization field also decreases from about $24 \mathrm{mV} / \mathrm{m}$ to about 10 $\mathrm{mV} / \mathrm{m}$ in the presence of turbulent terms (or the peak current decreases from approx. $14 \mathrm{Amp} \mathrm{km}^{-2}$ to approx. 8-9 Amp km ${ }^{-2}$ ). Thus, the inclusion of anomalous mobility due to short-wavelength turbulence in the large-scale dynamics leads to substantial improvement in the linear theory predictions and a better conformity to experimental data.

The results of Gangepain et al. (1977) indicate that large values of electric conductivity (fourfold that of laboratory values) are needed to describe the electrojet parameters in models, however a comparison of all models is beyond the scope of this study in which we wish to report the observed features of the electrojet from simultaneous in-situ measurements and to estimate the electron drift and electric field from the limited data set that exists.

\section{Conclusion}

Simultaneous in-situ measurements of the current density and electron density from four rocket flights from Thumba (India) and one from Peru show that peak current density occurs at 106-107 km over Thumba and at $109 \mathrm{~km}$ over Peru. This is consistent with the result of model studies carried out by Richmond (1973) in which increases in the geomagnetic field reduces the Pederson and Hall conductivities at all levels and also lowers the altitude of the maximum polarization field and reduces the strength of the electrojet. Electron drift velocity and electric field estimated from these measurements show a peak around 105-109 km. This is also consistent with the VHF radar results. The electric field shows large variability and plays an important role in the day-to-day variability of the equatorial electrojet.

Acknowledgments. Thanks are due to Profs. Satya Prakash and T. S. G. Sastry for providing the electron density and current density data used in the analyses. The ground geomagnetic data were obtained through the World Data Centre for STP, Boulder, Colorado, USA. Thanks are also due to Profs. H. S. S. Sinha and S. P. Gupta for their discussions and help. 


\section{References}

Baker, N. G. and D. F. Martyn, Electric currents in the ionosphere; The conductivity, Philos. Trans. Roy. Soc. Lond., A246, 281-294, 1953.

Carter, D. A., B. B. Balsley, and W. L. Eckerland, VHF Dopler radar observations of the African Equatorial Electrojet, J. Geophys. Res., 81, 2786-2794, 1976.

Chandra, H., R. K. Misra, and R. G. Rastogi, Equatorial ionospheric drift and electrojet, Planet. Space Sci., 19, 1497-1503, 1971.

Chandra, H., H. S. S. Sinha, and R. G. Rastogi, Equatorial electrojet studies from rocket and ground measurements, Earth Planets Space, 52, 111120, 2000.

Chapman, S., The equatorial electrojet as detected from the abnormal electric current distributions above Huancayo, Arch. Meteoral. Geophys. Bioclimatal, A4, 368-390, 1951.

Cowling, T. G. and R. Borger, Electrical conductivity in the ionosphere, Nature (Lond), 162, 143, 1948.

Fambitakoye, O., R. G. Rastogi, J. Tabagh, and P. Vila, Counter electrojet and $E_{\mathrm{sq}}$ disappearance, J. Atmos. Terr. Phys., 35, 1119-1126, 1973.

Gangepain, J., M. Crochet, and A. D. Richmond, Comparison of equatorial electrojet models, J. Atmos. Terr. Phys., 39, 1119-1124, 1977.

Maynard, N. C., Measurements of ionospheric currents off the coast of Peru, J. Geophys. Res., 72, 1863-1875, 1967.

Pfaff, R. F. Jr., M. H. Acuna, P. A. Marionni, and N. B. Trivedi, DC polarization electric field and current density and plasma density measurements in the daytime eqatorial electrojet, Geophys. Res. Lett, 24, 16671670, 1997.

Prakash, S. and B. H. Subbaraya, Langmuir probe for the measurement of electron density and electron temperature in the ionosphere, Rev. Sci. Inst., 38, 1132-1136, 1967.

Rao, T. R. and S. Prakash, Electron plasma resonances detected by a mutual admittance probe in the equatorial ionosphere, Space Res., XVIII, 281-284, 1978.

Rastogi, R. G., Equatorial sporadic-E and plasma instabilities, Nature, 237, 73-75, 1972.

Rastogi, R. G., On the simultaneous existence of eastward and westward flowing equatorial electrojet currents, Proc. Indian Acad. Sci., A81, 8092, 1975.

Rastogi, R. G., Geomagnetic field variations at low latitudes and ionospheric electric field, J. Atmos. Terr. Phys., 55, 1375-1381, 1993.

Rastogi, R. G. and H. Chandra, Interplanetary magnetic field and the equatorial ionosphere, J. Atmos. Terr. Phys., 36, 377-379, 1974.

Rastogi, R. G. and A. Patil, A complex structure of equatorial electrojet current, Curr. Sci., 85, 433-436, 1986.

Rastogi, R. G., H. Chandra, and S. C. Chakravarty, The disappearance of equatorial $E_{S}$ and the reversal of electrojet current, Proc. Indian Acad.
Sci., 74, 62-67, 1971a.

Rastogi, R. G., H. Chandra, and R. K. Misra, Effect of magnetic activity on electron drifts in the equatorial electrojet region, Nature, 233, 13-15, $1971 \mathrm{~b}$.

Rastogi, R. G., H. Chandra, and R. K. Misra, Features of the ionospheric drift over the magnetic equator, Space Res., XII, 983-992, 1972.

Richmond, A. D., Equatorial electrojet, I, Development of a model including winds and instabilities, J. Atmos. Terr. Phys., 35, 1083-1103, 1973.

Ronchi, C., R. N. Sudan, and P. L. Similon, Effect of short-scale turbulence on kilometer wavelength irregularities in the equatorial electrojet, $J$. Geophys. Res., 95, 189-200, 1990.

Sastry, T. S. G., Quiet day electrojet over Thumba, India, J. Geophys. Res., 73, 1789-1794, 1968.

Sastry, T. S. G., Diurnal change in the parameters of the equatorial electrojet as observed by rocket-borne magnetometers, Space Res., X, 778$785,1970$.

Sastry, T. S. G., Daily variations of geomagnetic field at the Indian stations under the electrojet during the period of the July 1966 proton flare, $J$. Geophys. Res., 78, 1692-1698, 1973.

Sinha, H. S. S. and S. Prakash, Electron densities in the equatorial lower ionosphere over Thumba and SHAR, Adv. Space Res., 18, 311-318, 1996.

Sinha, H. S. S., H. Chandra, and R. G. Rastogi, Longitudinal inequalities in the equatorial electrojet, Proc. Nat. Acad. Sci. India, 69(A), 89-96, 1999.

Subbaraya, B. H., S. Prakash, and S. P. Gupta, Electron densities in the equatorial equatorial lower ionosphere from the Langmuir probe experiments conducted at Thumba during the year 966-1978, Scientific report ISRO-PRL-SR-15-83, 1983.

Subbaraya, B. H., P. Muralikrishna, T. S. G. Sastry, and S. Prakash, A study of the structures of electrical conductivities and the electrostatic field within the equatorial electrojet, Planet. Space Sci, 20, 47-52, 1972.

Sugiura, M. and D. J. Poros, An improved model equatorial electrojet with a meridional current system, J. Geophys. Res., 74, 4025-4034, 1969.

Tiwari, D., A. K. Patra, K. S. Viswanathan, N. Jyoti, C. V. Devasia, K. S. V. Subbarao, and R. Sridharan, Simulatenous radar observations of electrojet plasma irregularities at 18 and $54.95 \mathrm{MHz}$ over Trivandrum, India, J. Geophys. Res., 108(A10), 1368, doi:10.1029/2002JA009698, 2003.

Untiedt, J., A model of the equatorial electrojet involving meridional currents, J. Geophys. Res., 72, 5799-5810, 1967.

R. G. Rastogi and H. Chandra (e-mail: hchandra@prl.res.in) 